\title{
Portal hypertensive biliopathy and bile duct varices presenting as jaundice
}

A 61-year-old woman with advanced alcoholic liver cirrhosis (Child - Pugh score: C, 10 points; MELD score: 24 points) developed evident jaundice with prevalent conjugated hyperbilirubinemia (bilirubin: total $12.0 \mathrm{mg} / \mathrm{dL}$, direct $7.5 \mathrm{mg} / \mathrm{dL}$ ). Aminotransferases were only mildly elevated (AST 76U/L, ALT 40U/L), while there was a predominant elevation of alkaline phosphatase (162 U/L) and $\mathrm{y}$-glutamyl transpeptidase $(103 \mathrm{U} / \mathrm{L})$. Routine laboratory analysis also showed anemia (hemoglobin $9.8 \mathrm{~g} / \mathrm{dL}$ ), thrombocytopenia (platelets $25000 / \mu \mathrm{L})$, and prolonged prothrombin time (PT-INR 2.01). Ultrasonography showed dilated bile ducts. Magnetic resonance cholangiopancreatography (MRCP) revealed an abnormal biliary tree with multiple strictures and focal dilatations characterized by irregular contrast enhancement, potentially suggestive of intraductal malignancy, although no prominent obstruction was observed ( Fig.1a,b). Radiographic features of portal hypertension with perigastric and perisplenic collaterals were also observed. Neither esophageal nor gastric varices were found by esophagogastroduodenoscopy, while congestive gastropathy was present. Endoscopic retrograde cholangiopancreatography (ERCP) was carried out with the aim of defining the diagnosis and facilitating biliary drainage. ERCP documented multiple narrowing of intra- and extrahepatic bile ducts without major stenosis ( $>$ Fig. 1c). The still unexplained biliary strictures prompted performance of peroral cholangioscopy (\$Fig.1d; Video 1). Biliary sphincterotomy was performed to be able to pass the cholangioscope. Peroral digital single-operator cholangioscopy (SpyGlass DS; Boston Scientific) revealed multiple bile duct varices (BDV) with red spots and microbleedings localized to the common bile duct, thereby defining a diagnosis of portal biliopathy. Neither a critical (i.e., clinically significant) stenosis nor blood clots causing obstruction were found. Therefore, no en-
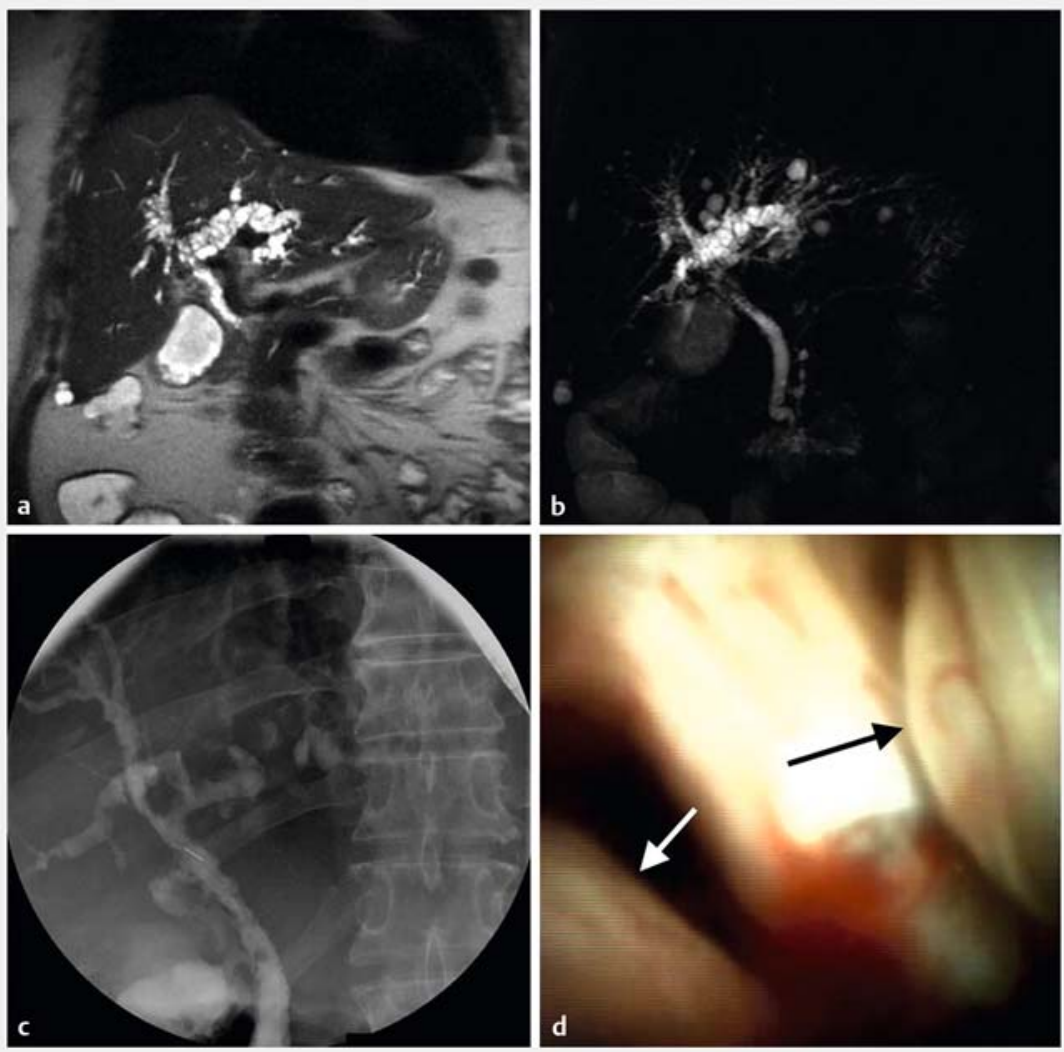

- Fig. 1 Imaging studies of abnormal biliary tree: a, b magnetic resonance cholangiopancreatography, $\mathbf{c}$ endoscopic retrograde cholangiopancreatography, $\mathbf{d}$ peroral cholangioscopy. Arrows in $\mathbf{d}$ indicate bile duct varices.

doscopic treatment was performed. The patient remained clinically stable on follow-up, although no substantial improvement of jaundice was observed (bilirubin: total $13.2 \mathrm{mg} / \mathrm{dL}$, direct $7.7 \mathrm{mg} / \mathrm{dL}$ ). She accepted an offer to participate in a program of alcohol counseling and, finally, after 6 months of abstinence from alcohol, was considered for liver transplantation.

The term portal biliopathy refers to biliary obstruction associated with cavernous transformation of the portal venous system. Jaundice is its main clinical manifestation, but cholangitis and hemobilia may also be present. The diagnosis of portal biliopathy requires three criteria to be fulfilled: (i) presence of portal cavernoma and/or hypertension, (ii) typical cholangiographic changes (e.g., irregular ductal contour, strictures and dilatations) on ERCP/MRCP, and (iii) absence of other conditions that cause similar changes (e.g., neoplasms, primary sclerosing cholangitis, choledocholithiasis) [1].

Although BDV have been known about for decades [2,3], their diagnosis is still a clinical challenge for which a high index of suspicion is crucial [4]. BDV should be considered in the differential diagnosis of obstructive jaundice, especially in patients with known portal cavernoma and/or hypertension when medical im- 


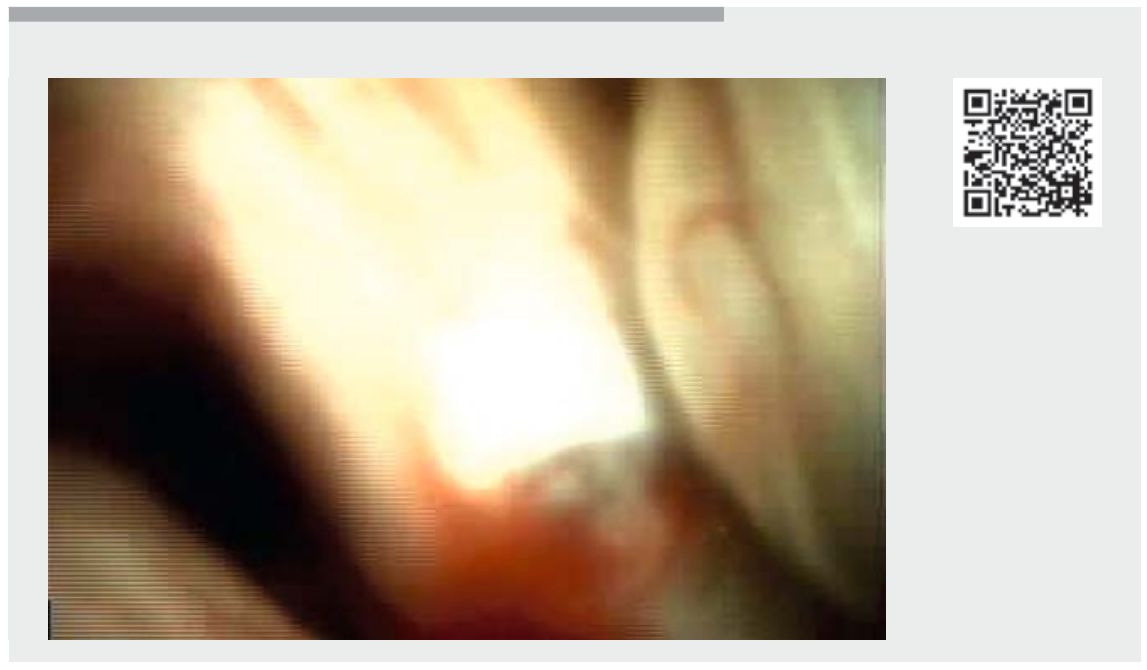

$\checkmark$ Video 1 Multiple bile duct varices with red spots and microbleedings localized to the common bile duct on peroral cholangioscopy.

aging is inconclusive. Peroral cholangioscopy, allowing direct visualization of the biliary tract, may be a useful diagnostic tool for uncovering the causes of indeterminate biliary anomalies [5].

Endoscopy_UCTN_Code_CCL_1AZ_2AZ

\section{Competing interests}

The authors declare that they have no conflict of interest.

The authors

Gloria Tacchella ${ }^{1}$, Odenca Gjermeni ${ }^{1}$, Stefano Francesco Crinó $^{2}$, Armando Gabbrielli², Nicola Martinelli ${ }^{1} \odot$

1 Department of Medicine, University of Verona, Italy

2 Gastroenterology and Digestive Endoscopy Unit, The Pancreas Institute, Policlinico G. B. Rossi, University Hospital, Verona, Italy
Corresponding author

Nicola Martinelli, MD, PhD

Department of Medicine, University of Verona, Policlinico G. B. Rossi, Piazzale L. A. Scuro 10, 37134 Verona, Italy nicola.martinelli@univr.it

\section{References}

[1] Chawla Y, Agrawai S. Portal cavernoma cholangiopathy - history, definition and nomenclature. J Clin Exp Hepatol 2014; 4: S15-S17

[2] Gibson JB, Johnston GW, Fulton TT et al. Extrahepatic portal venous obstruction. $\mathrm{Br}$ ] Surg 1965; 52: 129-139

[3] Williams SM, Burnett DA, Mazer M]. Radiographic demonstration of common bile duct varices. Gastrointest Radiol 1982; 7: 69-70

[4] Zulli C, Sica M, Caruso A et al. A rare case of biliary tract stenosis caused by intraductal varices diagnosed by single-operator peroral cholangioscopy. Gastrointest Endosc 2016; 84: 1052-1053

[5] Pérez-Cuadrado-Robles E, Deprez PH. Indications for single-operator cholangioscopy and pancreatoscopy: an expert review. Curr Treat Options Gastroenterol 2019; 17: 408419

Bibliography

Endoscopy 2021; 53: E442-E443

DOI 10.1055/a-1337-1994

ISSN 0013-726X

published online 27.1.2021

(C) 2021. Thieme. All rights reserved.

Georg Thieme Verlag KG, Rüdigerstraße 14 , 70469 Stuttgart, Germany

\section{ENDOSCOPY E-VIDEOS}

https://eref.thieme.de/e-videos

回回 Endoscopy E-Videos is a free 整 access online section, reporting 回: on interesting cases and new techniques in gastroenterological endoscopy. All papers include a high quality video and all contributions are freely accessible online. 